\title{
Contribution of animal products to dietary intakes in the very old
}

\author{
N. Mendonça ${ }^{1,3}$, A. Granic ${ }^{2}$, J.C. Mathers ${ }^{2,3}$,W. Wrieden ${ }^{3}$, M. Siervo ${ }^{2,3}$, C. Seal ${ }^{1,3}$, C. Jagger ${ }^{2}$, \\ A.J. Adamson ${ }^{2,3}$ and T.R. Hill ${ }^{1,3}$
}

${ }^{1}$ School of Agriculture Food and Rural Development, ${ }^{2}$ Newcastle University Institute for Ageing and ${ }^{3}$ Human Nutrition Research Centre, Newcastle University, NE1 7RU, Newcastle upon Tyne, UK

Animal derived foods supply not only high-quality protein but are also a rich source of several vitamins and minerals.

We aimed to assess the contribution of animal-based foods to dietary intake in 793 eighty-five year-olds (302 men and 491 women) living in North-East England and participating in the Newcastle 85+ cohort study ${ }^{(1)}$ (see http://research.ncl.ac.uk/85plus for further details).

Dietary information was collected at baseline in 2006/2007 using a repeated multiple pass 24 -hour recall $(2 \times 24 \mathrm{hr}$-recall). Energy, macronutrient, vitamin and mineral intakes were estimated using the McCance and Widdowson's Composition of Foods $6^{\text {th }}$ edi$\operatorname{tion}^{(2)}$. Contribution (\%) to dietary intake was estimated based on five composite animal-based food groups viz. meat and meat products, milk and milk products, butter, egg and egg dishes and, fish and fish dishes and 11 other non-animal based food groups.

\begin{tabular}{|c|c|c|c|c|c|}
\hline & Meat and Meat Products & Milk and Milk Products & Butter & Egg and Egg dishes & Fish and Fish dishes \\
\hline Consumers $(\%)$ & 94 & 90 & 45 & 39 & 36 \\
\hline \multicolumn{6}{|l|}{ Nutrients } \\
\hline Energy $(\%)$ & $14 \cdot 5$ & $9 \cdot 0$ & $3 \cdot 8$ & $2 \cdot 3$ & $2 \cdot 5$ \\
\hline Total Fat $(\%)$ & $20 \cdot 8$ & $12 \cdot 1$ & $10 \cdot 3$ & $4 \cdot 4$ & $3 \cdot 2$ \\
\hline SFA $(\%)$ & $20 \cdot 9$ & $19 \cdot 1$ & $17 \cdot 7$ & $3 \cdot 9$ & 1.7 \\
\hline MUFA (\%) & $32 \cdot 9$ & $13 \cdot 3$ & $11 \cdot 1$ & $5 \cdot 5$ & 4.7 \\
\hline Protein $(\%)$ & $34 \cdot 6$ & $11 \cdot 5$ & $0 \cdot 1$ & $3 \cdot 7$ & $6 \cdot 4$ \\
\hline Vitamin A $(\%)$ & $39 \cdot 9$ & $9 \cdot 4$ & $7 \cdot 3$ & $3 \cdot 6$ & $0 \cdot 5$ \\
\hline Vitamin B12 (\%) & $53 \cdot 2$ & $12 \cdot 5$ & $0 \cdot 0$ & $5 \cdot 6$ & $17 \cdot 3$ \\
\hline Vitamin D (\%) & $16 \cdot 4$ & $4 \cdot 6$ & $1 \cdot 7$ & $9 \cdot 8$ & $33 \cdot 8$ \\
\hline Calcium $(\%)$ & $4 \cdot 1$ & $31 \cdot 3$ & $0 \cdot 2$ & $2 \cdot 3$ & $2 \cdot 8$ \\
\hline Iron $(\%)$ & $16 \cdot 5$ & 1.7 & $0 \cdot 2$ & $3 \cdot 4$ & $2 \cdot 0$ \\
\hline Selenium $(\%)$ & $20 \cdot 7$ & $4 \cdot 8$ & $0 \cdot 0$ & $3 \cdot 6$ & 11.9 \\
\hline Zinc $(\%)$ & $34 \cdot 2$ & $10 \cdot 4$ & $0 \cdot 1$ & $3 \cdot 0$ & $2 \cdot 3$ \\
\hline
\end{tabular}

SFA, saturated fatty acids. MUFA, monounsaturated fatty acids.

Misreporting was not accounted for in the main analysis but estimated at $17 \%(\mathrm{n}=124)$. Animal derived foods contributed between $24 \%$ and $89 \%$ to selected nutrients' intake. More than half $(56 \cdot 3 \%)$ of protein intake was derived from these food groups. Half and $94 \%$ of the meat and meat products contribution to vitamin B12 and vitamin A intake, respectively, came from liver and liver dishes. Animal based foods are an important source of several macro and micronutrients in this age group.

1. Collerton J, Davies K, Jagger C et al. (2009) Health and disease in 85 year olds: baseline findings from the Newcastle $85+$ cohort study. BMJ 339, b4904.

2. Food Standards Agency (2002) McCance and Widdowson's The Composition of Foods, Sixth summary edition. Cambridge: Royal Society of Chemistry. 